\title{
Correction to: Similar genetic diversity but increased differentiation revealed among a 58-year-old Pinus massoniana seed-tree stand and its progenies generated at different ages
}

\author{
Tian-Dao Bai ${ }^{1} \cdot$ Mei-Xi Chen ${ }^{1} \cdot$ Jin-Pei Ye ${ }^{2} \cdot$ Wei-Xin Jiang $^{1}$ (D) Zhang-Qi Yang $^{3}$
}

Published online: 4 March 2021

๑) Springer-Verlag GmbH Germany, part of Springer Nature 2021

\section{Correction to: European Journal of Forest Research https://doi.org/10.1007/s10342-021-01353-4}

In the original publication of the article, the funding information was missed. It has been given in this correction.

The original article has been corrected.

Funding This work was supported by National Natural Science Foundation of China (No. 31400575) and Natural Science Foundation of Guangxi (No. 2018GXNSFBA281110).
Publisher's Note Springer Nature remains neutral with regard to jurisdictional claims in published maps and institutional affiliations.

The original article can be found online at https://doi.org/10.1007/ s10342-021-01353-4.

Wei-Xin Jiang

jwx_1985@163.com

1 Key Laboratory of National Forestry and Grassland Administration for Fast-Growing Wood Breeding and Cultivation in Central and South China, College of Forestry, Guangxi University, Nanning, China

2 Tianhongling State-Owned Forest Farm, Cangwu, Guangxi, China

3 Guangxi Academy of Forestry, Nanning, China 